\title{
Inhibition of muscle glycogen synthase activity and non-oxidative glucose disposal during hypoglycaemia in normal man
}

\author{
L. Orskov ${ }^{1}$, J. F. Bak ${ }^{1}$, N. Abildgård ${ }^{3}$, O.Schmitz ${ }^{2}$, F. Andreasen ${ }^{4}$, E. A. Richter ${ }^{5}$, C. Skjærbæk ${ }^{3}$, N. Møller ${ }^{2}$ \\ Department of Medicine $\mathrm{C}^{1}$ and $\mathrm{M},{ }^{2}$ Åarhus University Hospital, Åarhus, Denmark \\ ${ }^{3}$ Institute of Experimental Clinical Research and ${ }^{4}$ Department of Pharmacology, University of Åarhus, Åarhus, Denmark \\ ${ }^{5}$ Copenhagen Muscle Research Centre, August Krogh Institute, University of Copenhagen, Copenhagen, Denmark
}

Summary The purpose of the present study was to evaluate the role of muscle glycogen synthase activity in the reduction of glucose uptake during hypoglycaemia. Six healthy young men were examined twice; during $120 \mathrm{~min}$ of hyperinsulinaemic $\left(1.5 \mathrm{mU} \cdot \mathrm{kg}^{-1}\right.$. $\mathrm{min}^{-1}$ ) euglycaemia followed by: 1) $240 \mathrm{~min}$ of graded hypoglycaemia (plasma glucose nadir $2.8 \mathrm{mmol} / \mathrm{l}$ ) or 2) $240 \mathrm{~min}$ of euglycaemia. At $350-360 \mathrm{~min}$ a muscle biopsy was taken and indirect calorimetry was performed at 210-240 and 330-350 min. Hypoglycaemia was associated with markedly increased levels of adrenaline, growth hormone and glucagon and also with less hyperinsulinaemia. During hypoglycaemia the fractional velocity for glycogen synthase was markedly reduced; from $29.8 \pm 2.3$ to $6.4 \pm 0.9 \%$, $p<0.05$. Total glucose disposal was decreased during hypoglycaemia $\left(5.58 \pm 0.55 \mathrm{vs} 11.01 \pm 0.75 \mathrm{mg} \cdot \mathrm{kg}^{-1}\right.$. min $^{-1}$ (euglycaemia); $p<0.05$ ); this was primarily due to a reduction of non-oxidative glucose disposal $\left(2.43 \pm 0.41\right.$ vs $7.15 \pm 0.7 \mathrm{mg} \cdot \mathrm{kg}^{-1} \cdot \mathrm{min}^{-1}$ (euglycaemia); $p<0.05)$, whereas oxidative glucose disposal was only suppressed to a minor degree. In conclusion hypoglycaemia virtually abolishes the effect of insulin on muscle glycogen synthase activity. This is in keeping with the finding of a marked reduction of non-oxidative glucose metabolism. [Diabetologia (1996) 39: 226-234]

Key words Hypoglycaemia, counter-regulation, glucose disposal, muscle glycogen synthase activity, glucose mass effect.
Hypoglycaemic episodes represent a major treatment-induced problem [1-5]. Severe hypoglycaemia is more frequent in patients receiving intensive insulin treatment, and the recent results from the Diabetes Control and Complications trial (DCCT) [6], proving the benefit of strict metabolic control on late diabetic complications, may be anticipated to enhance this problem.

Received: 17 May 1995 and in revised form: 19 July 1995

Corresponding author: Dr. L. Ørskov, Department of Medicine C, Åarhus, Amtssygehus, DK-8000, Aarhus C, Denmark Abbreviations: HGP, Hepatic glucose production; Rd, glucose disposal; $\mathrm{GH}$, growth hormone; 3-OHB, 3-hydroxybutyrate; G 6-P, glucose 6-phosphate; NEFA, non-esterified fatty acids; PP-1, phosphatase-1; Ra, rate of appearance; Rd-nonox, nonoxidative glucose disposal; Rd-ox, oxidative glucose disposal; A0.5, half-maximal activity.
In studies involving short-term and more prolonged insulin infusion as well as the pituitary-adrenal-pancreatic-clamp technique [7-10] the present concept of hypoglycaemic counter-regulation has emerged; within minutes of lowering the plasma glucose level the combined effects of suppressed endogenous insulin secretion, increased secretion of glucagon and epinephrine, as well as glucose autoregulation [11], lead to enhanced hepatic glucose production (HGP) and reduced glucose disposal (Rd). With more prolonged $(2 \mathrm{~h})$ hypoglycaemia, the effects of increased growth hormone $(\mathrm{GH})$ and cortisol secretion also become evident. Increased substrate availability, serving as an independent fuel source (non-esterified fatty acids [NEFA], ketones) and as gluconeogenic precursors (lactate, amino acids, glycerol) also participate [12-16].

HGP is known to be increased both due to increased glycogenolysis and increased gluconeogene- 
sis [15-17], whereas the mechanism behind the suppressed glucose utilisation, which becomes more important with more prolonged hypoglycaemia [9], is less well described. In recent studies we and others have demonstrated that muscle glucose uptake is dramatically reduced during hypoglycaemia in healthy man [18-20]. However, the specific cellular events involved in this phenomenon require further examination.

To clarify this issue we employed hyperinsulinaemia-induced hypoglycaemia combined with muscle biopsies and indirect calorimetry to assess muscle glycogen synthase activity, intramuscular glucose and glucose 6-phosphate (G 6-P) content and the relative importance of oxidative- and non-oxidative glucose disposal in the defence against hypoglycaemia.

\section{Subjects and methods}

Subjects. Six healthy young volunteers participated in the study. Mean age was $25 \pm 1.7$ years; BMI, $22.2 \pm 0.9 \mathrm{~kg} / \mathrm{m}^{2}$. The study protocol was approved by the local ethical committee, and all subjects gave informed consent.

\section{Experimental protocol (Fig.1)}

Each subject underwent two studies, i.e. hypoglycaemic and euglycaemic, with an interval of approximately 1 month.

Both studies commenced at 08.00 hours after an overnight fast. Two catheters were placed; one in a heated dorsal hand vein for sampling of arterialized blood, another in the contralateral antecubital vein for infusions. Throughout both studies, human insulin (Insulin Actrapid human; Novo-Nordisk, Copenhagen, Denmark) was infused at a rate of $1.5 \mathrm{mU}$. $\mathrm{kg}^{-1} \cdot \mathrm{min}^{-1}$ and $\left(3-{ }^{3} \mathrm{H}-\right.$ ) glucose (Du Pont New-England Nuclear, Boston, Mass., USA) in a primed $(30 \mu \mathrm{Ci})$ continuous $(0.3 \mu \mathrm{Ci} / \mathrm{min})$ manner, in order to determine glucose turnover. $3^{3}{ }^{3} \mathrm{H}$-glucose batches contained no contaminating radiochemicals as assessed by HPLC.

Glucose clamp. Glucose (55 and $200 \mathrm{~g} / 1)$ was infused at variable rates to obtain the desired plasma glucose level. Throughout the control study and during the first $120 \mathrm{~min}$ of the hypoglycaemic study plasma glucose was clamped at $5 \mathrm{mmol} / \mathrm{l}$, to allow the isotope to equilibrate (these first 2 study hours are hereafter designated the equilibration period). In the hypoglycaemic study, hypoglycaemia was then induced (by reducing exogenous glucose administration) aiming at a nadir of $2.8 \mathrm{mmol} / 1$ (Fig. 1).

Blood sampling. Plasma glucose was measured every $5 \mathrm{~min}$ by a glucose analyser (Beckman Instruments, Palo Alto, Calif., USA). Blood for determination of glucose, glucose-specific activity, insulin, C-peptide, $\mathrm{GH}$, glucagon, epinephrine, norepinephrine, NEFA and blood metabolites was drawn as shown in Figures 2 and 3.

Muscle biopsy. At the end of each study (345-360 min) a muscle biopsy was obtained from the vastus lateralis muscle as previously described [21].

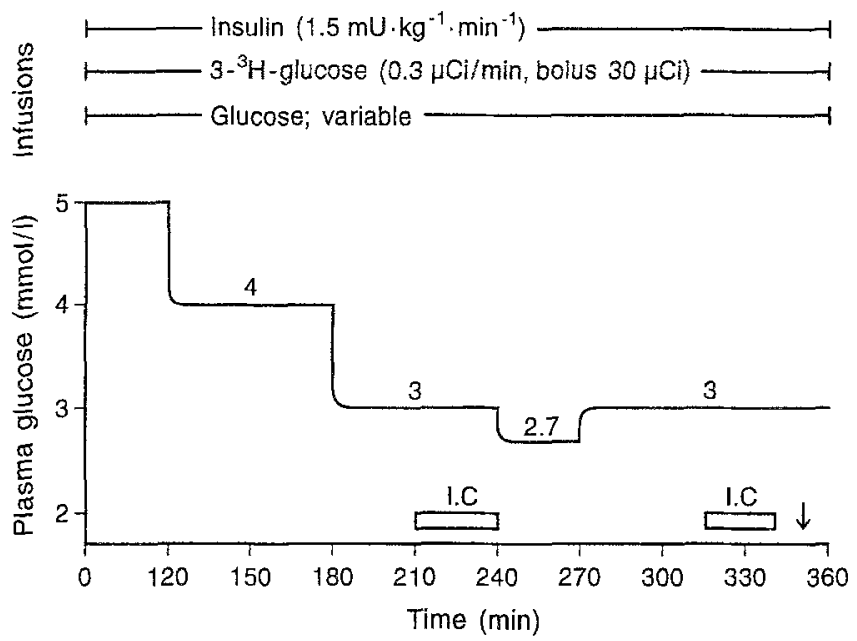

Fig. 1. Study design. I. C., indirect calorimetry; arrow indicates muscle biopsy

Indirect calorimetry. Energy expenditure and respiratory exchange ratio were measured at 210-240 and 320-340 min.

A computerized, open circuit system was employed to measure gas exchange across a 25-litr canopy (Deltatrac, Datex Instrumentarium Inc., Helsinki, Finland). The monitor determines carbon dioxide production and oxygen consumption by multiplying dry air flow through the canopy with alterations in gas concentration over the canopy. Estimated net glucose and lipid oxidation rates were calculated from the above measurements and protein oxidation rates were estimated from the urinary excretion rates of urea [22]. Net non-oxidative glucose disposal ( $\mathrm{Rd}$-nonox) was determined by subtracting oxidative glucose disposal ( $\mathrm{Rd}-\mathrm{ox}$ ) from total $\mathrm{Rd}$, measured isotopically.

\section{Analytical methods}

Plasma glucose was measured in duplicate immediately after sampling (Beckman Instruments). Plasma glucagon was determined by radioimmunoassay as previously described with the modification that ( $\mathrm{PEG}=$ poly ethylen glycol) was used for separation prior to determination and that plasma was extracted with ethanol [23]. Serum insulin was measured using a monoclonal sandwich assay with no cross-reaction with proinsulin or major split-products of insulin [24]. Serum C-peptide was assayed employing a commercial kit (Immunonuclear Corp., Stillwater, Minn., USA) while serum GH was measured using an immunofluorometric sandwich assay with two monoclonal antibodies (Delfia hGH kit; Wallac Oy, Turku, Finland). Catecholamines were determined by electrochemical detection following HPLC [25]. Serum NEFA were determined by a colorimetric method employing a commercial kit (Wako Chemicals, Neuss, Germany). Blood 3-hydroxybutyrate (3-OHB), glycerol, lactate and alanine were assayed by automated enzymatic fluorometric methods [26]. For determination of tritiated glucose activity, plasma was deproteinized using $0.3 \mathrm{~mol} / \mathrm{l} \mathrm{Ba}$ $(\mathrm{OH})_{2}$ and $5 \% \mathrm{ZnSo}_{4}$ after which the supernatant was evaporated under vacuum, resuspended in distilled water and counted by a liquid scintillation counter after the addition of $5 \mathrm{ml}$ Aqualuma Plus (Lumbac, Schaesburg, the Netherlands).

Muscle enzyme analysis. Glycogen synthase activity was measured as described previously [27] using $0.13 \mathrm{mmol} / \mathrm{l}$ UDP-U- 


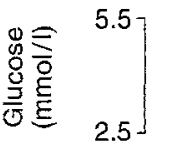

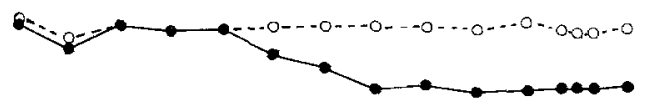

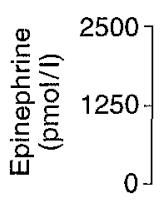

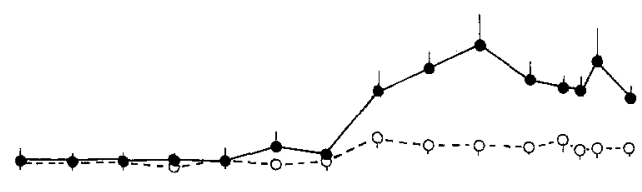

동종

$\left.\begin{array}{c}100 \\ 50 \\ 0\end{array}\right]$

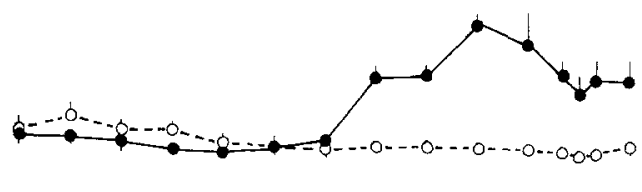

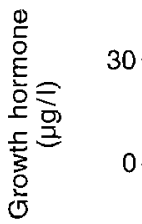

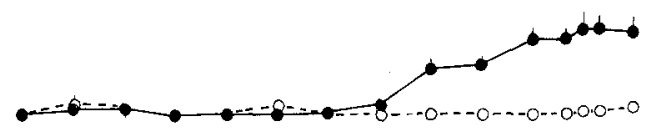

\begin{tabular}{lllcccc}
\hline 0 & 60 & 120 & 180 & 240 & 300 & 360 \\
Time (min) & & &
\end{tabular}

Fig. 2. Plasma glucose, serum epinephrine, plasma glucagon, serum $\mathrm{GH}$ concentrations during a hyperinsulinaemic, hypoglycaemic- (•) and euglycaemic clamp (O) in six healthy subjects

${ }^{14} \mathrm{C}$-glucose (DuPont-New England Nuclear), $0.67 \%(\mathrm{w} / \mathrm{v}) \mathrm{gly}-$ cogen, and $0-6.7 \mathrm{mmol} / \mathrm{l} \mathrm{G}$ 6-P (final concentrations). In this context, $1 \mathrm{U}$ of glycogen synthase activity equals the incorporation of $1 \mathrm{nmol}$ of UDP-glucose into glycogen per min. Total glycogen synthase activity is defined as the activity in the presence of a saturating concentration $(6.7 \mathrm{mmol} / \mathrm{l})$ of $\mathrm{G}$ 6-P. Fractional velocities were calculated as glycogen synthase activity in the presence of a subsaturating concentration of $\mathrm{G}$ 6-P $(0.07 \mathrm{mmol} / \mathrm{l})$ divided by glycogen synthase activity in the presence of $6.7 \mathrm{mmol} / 1 \mathrm{G}$ 6-P. The concentration of $\mathrm{G}$ 6-P giving half-maximal activity of the glycogen synthase (A0.5 for $G$ 6$P)$, representing a different mode of expressing glycogen synthase activity, was calculated using a Hill plot [28].

G 6-P, glucose and glycogen determination. G 6-P glucose- and glycogen content in the muscle biopsy were estimated according to Lowry and Passonneau [29]. Intramuscular glucose was corrected for glucose content in the extracellular space by subtracting the estimated glucose content in the extracellular space $(0.31 / \mathrm{kg}$ dry weight $\times$ plasma glucose $)$ from the total glucose content [30]. It is recognized that this is an estimate, as the exact extent of extracellular water is uncertain, especially during hypoglycaemia.

\section{Statistical analysis}

The rates of total glucose appearance $(\mathrm{Ra})$ and total $\mathrm{Rd}$ were determined from tritiated glucose data in samples taken every $15 \mathrm{~min}$ throughout the study. The values were calculated according to the non-steady-state equations of Steele [31] as modified by DeBodo et al. [32]. A distribution volume of $220 \mathrm{ml} / \mathrm{kg}$ and a pool fraction of 0.65 was employed. HGP was
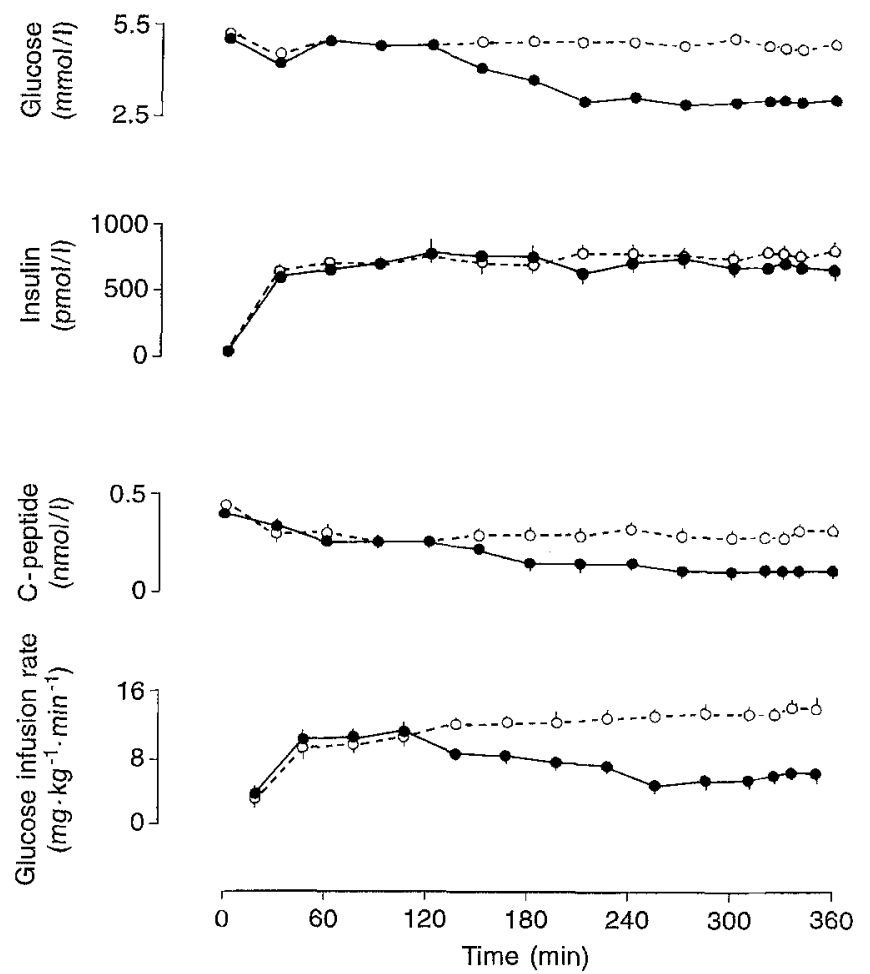

Fig. 3. Plasma glucose, serum insulin and C-peptide concentrations and glucose infusion rates during a hyperinsulinaemic, hypoglycaemic- (•) and euglycaemic clamp (O) in six healthy subjects

calculated by subtracting the glucose infusion rate (GIR) from Ra.

All values are expressed as mean \pm SEM. Two-way analysis of variance with repeated measures for two factors (time and treatment) was employed a priori to test for changes with time and between treatments. If this test revealed significant differences the Student's $t$-test for paired data was used to further assess differences between experiments.

\section{Results}

Glucose and hormones (Figs. 2, 3). Basal plasma glucose levels $(\mathrm{t}=0)$ were similar in the two studies ( $5.1 \pm 0.2$ vs $5.3 \pm 0.1 \mathrm{mmol} / \mathrm{l}$, euglycaemia vs hypoglycaemia). Likewise plasma glucose levels did not differ during the first $2 \mathrm{~h}$ of the study ( $\mathrm{t}, 0$ $120 \mathrm{~min}=$ equilibration period). Throughout the rest of the hypoglycaemic study plasma glucose levels were kept lower, reaching a mean minimum of $2.9 \pm 0.1 \mathrm{mmol} / 1$ after $270 \mathrm{~min}$ (Fig. 2).

Basal and equilibration levels of epinephrine, norepinephrine, $\mathrm{GH}$ and glucagon were similar in the two studies. During euglycaemia epinephrine levels remained stable with a mean value of $589 \pm$ $164 \mathrm{pmol} / 1$ at $\mathrm{t} 240-360 \mathrm{~min}$. During hypoglycaemia levels increased significantly $(p<0.05)$, reaching a maximum value of $2123 \pm 486 \mathrm{pmol} / 1$ at $270 \mathrm{~min}$.

GH levels were stable in the euglycaemic study with a mean value of $1.5 \pm 0.5 \mu \mathrm{g} / 1$ at $240-360 \mathrm{~min}$. 


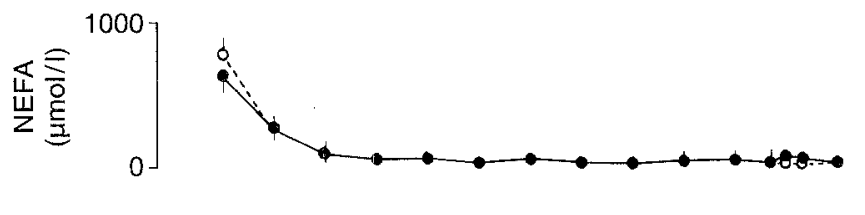

Table 1. Individual values of fractional velocity (FV) of glycogen synthase activity at $0.07 \mathrm{mmol} / 1 \mathrm{G} 6-\mathrm{P}$ in muscle biopsies during euglycaemia and hypoglycaemia

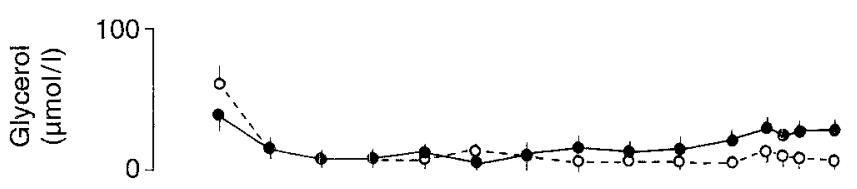

\begin{tabular}{lll}
\hline Subject & FV (\%) & FV $(\%)$ \\
& Euglycaemia & Hypoglycaemia \\
\hline 1 & 25.7 & 7.3 \\
2 & 34.2 & 5.7 \\
3 & 34.5 & 6.3 \\
4 & 23.9 & 9.8 \\
5 & 36.0 & 3.4 \\
6 & 24.3 & 6.3 \\
\hline
\end{tabular}
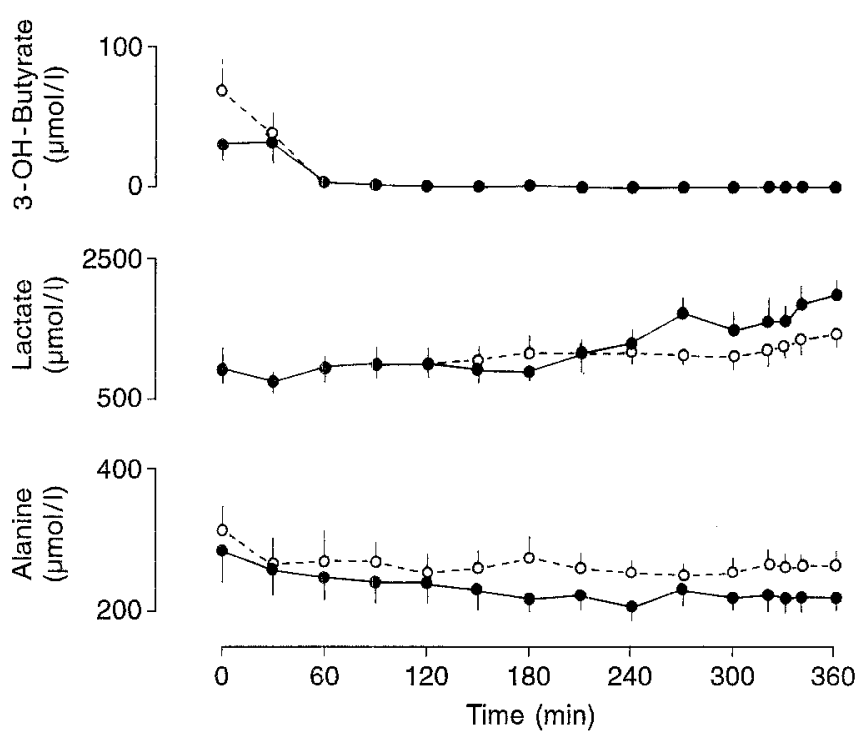

Fig. 4. Concentrations of serum NEFA, blood glycerol, 3$\mathrm{OHB}$, lactate and alanine during a hyperinsulinaemic, hypoglycaemic- (•) and euglycaemic clamp (O) in six healthy subjects

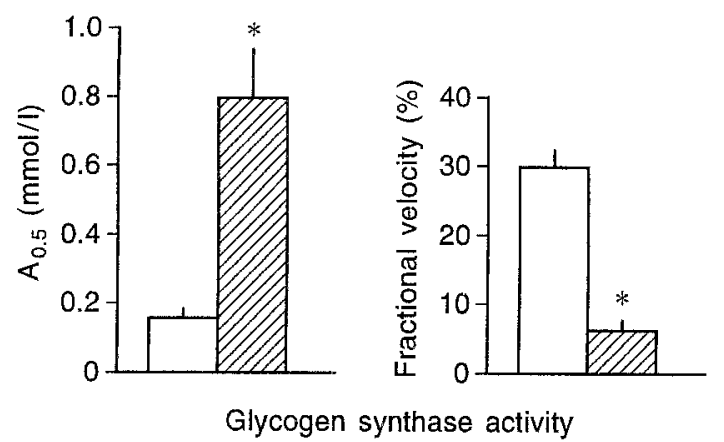

Fig. 5. Fractional velocities of glycogen synthase at $0.07 \mathrm{mmol} / \mathrm{l}$ $\mathrm{G}$ 6-P in muscle biopsies and corresponding half-maximal activation constants (A 0.5) for G 6-P during a hyperinsulinaemic, euglycaemic- $(\square)$ and hypoglycaemic clamp (Y) in six healthy subjects. Values are mean \pm SEM. ${ }^{*} p<0.05$

During hypoglycaemia levels increased sharply to $14.0 \pm 3.8 \mu \mathrm{g} / \mathrm{l}$ when plasma glucose was lowered to $3 \mathrm{mmol} / \mathrm{l}$ and stabilized at $21.2 \pm 0.01 \mu \mathrm{g} / 1$ during the last $2 \mathrm{~h}(p<0.05)$.

Glucagon levels were reduced to a similar extent during the equilibration period. In the euglycaemic study levels stabilized thereafter $(17 \pm 3 \mathrm{ng} / \mathrm{l}$, at $\mathrm{t}$, 240-360 min). During hypoglycaemia glucagon levels

increased significantly reaching a maximum of $88 \pm 6 \mu \mathrm{g} / \mathrm{l}$ at $270 \mathrm{~min}(p<0.05)$.

Basal insulin levels were similar at $37 \pm 4$ and $36 \pm 4 \mathrm{pmol} / 1$ (euglycaemia vs hypoglycaemia, NS); insulin infusion caused levels to increase to a mean level of $756 \pm 30 \mathrm{pmol} / 1$ during the last $2 \mathrm{~h}$ in the euglycaemic study, whereas during hypoglycaemia, levels were slightly lower $(684 \pm 60 \mathrm{pmol} / 1, p<0.05)$.

During insulin infusion an initial reduction in Cpeptide levels was seen in both studies $(0.43 \pm$ $0.03 \mathrm{nmol} / 1$ at basal to $0.26 \pm 0.03 \mathrm{nmol} / 1$ at $120 \mathrm{~min}$ during euglycaemia). Hypoglycaemia caused C-peptide levels to be further reduced after $240 \mathrm{~min}$ $(0.13 \pm 0.03 \mathrm{nmol} / 1)$, whereas levels were stable in the control study $(0.3 \pm 0.03 \mathrm{nmol} / 1, p<0.05)$.

Gluconeogenic precursors and lipid intermediates (Fig.4). From a baseline level of $774 \pm 115$ vs $642 \pm$ $108 \mu \mathrm{mol} / 1$ (euglycaemia vs hypoglycaemia, NS) insulin infusion suppressed NEFA levels equally ( $43 \pm 1$ vs $68 \pm 18 \mu \mathrm{mol} / 1$, euglycaemia vs hypoglycaemia, NS).

Insulin infusion caused a similar initial suppression of glycerol levels to $8 \pm 4$ vs $12 \pm 4 \mu \mathrm{mol} / \mathrm{l}$ (NS). In the euglycaemic study values then stabilized ( $8 \pm 3 \mu \mathrm{mol} / 1$, during the last 2 study hours), whereas during hypoglycaemia there was a small breakthrough in glycerol concentration $(26 \pm 5 \mu \mathrm{mol} / 1$, $p<0.05$ ).

Insulin infusion totally suppressed 3-OHB levels in both studies.

During hyperinsulinaemic euglycaemia, blood lactate concentrations increased slightly but significantly with time from a basal level of $873 \pm 106$ to $1243 \pm 129 \mu \mathrm{mol} / \mathrm{l}$ during the last $2 \mathrm{~h}(p<0.05)$. During the last $2 \mathrm{~h}$ of hypoglycaemia, a more pronounced increase occurred $(1675 \pm 220 \mu \mathrm{mol} / 1, p<0.05)$.

In both studies alanine levels fell slightly with time and levels did not differ between the two studies.

Muscle enzymes (Fig. 5, Table 1). Total activities of glycogen synthase (measured at saturating levels of G 6-P and physiologic levels of UDP-glucose) were similar ( $44.8 \pm 3.2$ vs $49.5 \pm 4.2 \mathrm{U} / \mathrm{mg}$ protein, hypoglycaemia vs euglycaemia). 


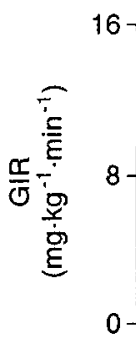

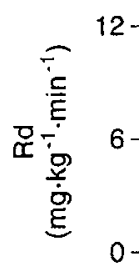

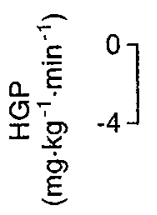

$90-120$

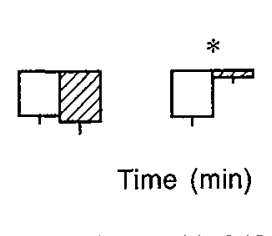

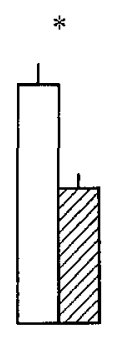
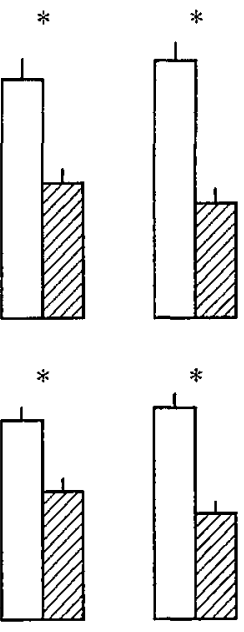

210-240

$320-340$
Fig. 6. Rates of glucose infusion (GIR), total glucose disappearance (Rd) and HGP during a hyperinsulinaemic, euglycaemic- $(\square)$ or hypoglycaemic clamp (ख) in six healthy subjects. Values are mean \pm SEM. $* p<0.05$
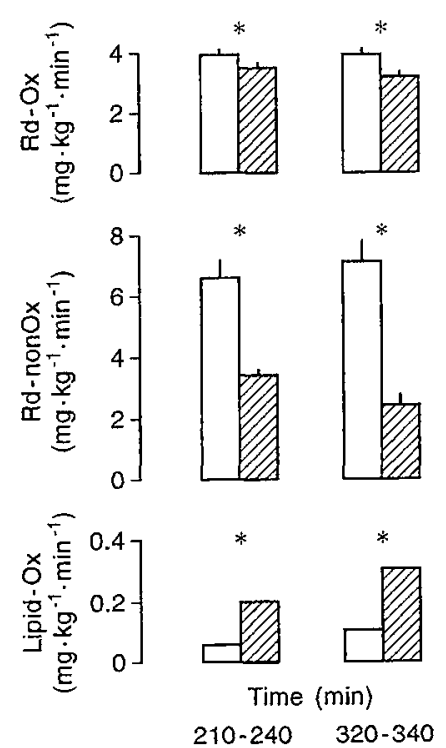

Fig. 7. Rates of oxidative glucose disposal ( $\mathrm{Rd}-\mathrm{ox}$ ), non-oxidative glucose disposal (Rd-nonOx) and lipid oxidation (lipidox) during a hyperinsulinaemic, euglycaemic- $(\square)$ or hypoglycaemic clamp (שT) in six healthy subjects. Values are mean \pm SEM. $* p<0.05$

Hypoglycaemia inhibited the fractional velocity (at $0.07 \mathrm{mmol} / \mathrm{l} \mathrm{G} 6-\mathrm{P}$ ) by $80 \%$ from $29.8 \pm 2.3$ to $6.4 \pm 0.9 \% \quad(p<0.05)$. Likewise the sensitivity of the glycogen synthase to $\mathrm{G}$ 6-P was reduced by hypoglycaemia as shown by an increase in $\mathrm{A} 0.5$ for G 6-P from $0.16 \pm 0.02$ to $0.8 \pm 0.15 \mathrm{mmol} / 1 \quad(p<$ $0.01)$.
$G$ 6-P, glucose and glycogen. The muscle content of $\mathrm{G}$ 6-P tended to be higher during hypoglycaemia; $0.68 \pm$ 0.12 vs $0.29 \pm 0.09 \mathrm{mmol} / \mathrm{kg}$ dry weight $(p=0.06)$. Due to technical problems, it was only possible to determine $\mathrm{G} 6-\mathrm{P}$ in five patients. The difference in calculated intramuscular glucose content $(1.49 \pm 0.32$ vs $1.16 \pm 0.39 \mathrm{mmol} / \mathrm{kg}$ dry weight, hypoglycaemia vs euglycaemia, $p=0.14$ ) did not reach statistical significance. Likewise it was not possible to detect any difference in glycogen content $(567 \pm 32$ vs $535 \pm$ $50 \mathrm{mmol} / \mathrm{kg}$ dry weight, hypoglycaemia vs euglycae$\operatorname{mia} ; p=\mathrm{NS}$ ).

Glucose kinetics (Fig.6). The glucose infusion rate was significantly lower throughout the hypoglycaemic period, reaching a minimum at $240-270 \mathrm{~min}$ $\left(4.85 \pm 1.15\right.$ vs $12.99 \pm 0.97 \mathrm{mg} \cdot \mathrm{kg}^{-1} \cdot \mathrm{min}^{-1}, \quad p<$ 0.001 ; hypoglycaemia vs euglycaemia).

$\mathrm{Rd}$ increased from a level of $8.70 \pm 0.91 \mathrm{mg} \cdot \mathrm{kg}^{-1}$. $\mathrm{min}^{-1}$ during the last $30 \mathrm{~min}$ of the equilibration period and stabilized at a level of $11.01 \pm 0.75 \mathrm{mg}$. $\mathrm{kg}^{-1} \cdot \min ^{-1}$ during the last $2 \mathrm{~h}$ of euglycaemia. During hypoglycaemia $\mathrm{Rd}$ was inhibited to a mean of $5.58 \pm$ $0.55 \mathrm{mg} \cdot \mathrm{kg}^{-1} \cdot \mathrm{min}^{-1}$ during the last $2 \mathrm{~h}(p<0.05)$.

$\mathrm{Ra}$ increased to a similar extent during the equilibration period. During euglycaemia levels then stabilized with a mean of $11.03 \pm 0.8 \mathrm{mg} \cdot \mathrm{kg}^{-1} \cdot \mathrm{min}^{-1}$ during the last $2 \mathrm{~h}$ whereas during hypoglycaemia a minimum was reached at $320 \mathrm{~min}(5.48 \pm 0.47$ vs $11.99 \pm 0.75 \mathrm{mg} \cdot \mathrm{kg}^{-1} \cdot \mathrm{min}^{-1}$, hypoglycaemia vs euglycaemia), whereafter levels increased slightly $\left(6.32 \pm \quad 0.61 \mathrm{mg} \cdot \mathrm{kg}^{-1} \cdot \mathrm{min}^{-1}\right.$ at $\left.340-360 \mathrm{~min}\right)$ $p<0.05)$.

HGP was suppressed to negative values in both studies. Equilibration levels ( $90-120 \mathrm{~min}$ ) were similar $\left(-2.57 \pm 0.62\right.$ vs $\left.-2.16 \pm 0.39 \mathrm{mg} \cdot \mathrm{kg}^{-1} \cdot \mathrm{min}^{-1}\right)$ During euglycaemia HGP continued to be excessively suppressed, whereas HGP was stimulated by hypoglycaemia $(-0.56 \pm 0.36$ vs $-2.73 \pm 0.44 \mathrm{mg}$. $\left.\mathrm{kg}^{-1} \cdot \min ^{-1}(320-340 \mathrm{~min}) ; p<0.05\right)$.

Indirect calorimetry (Fig. 7). Energy expenditure as calculated from oxygen consumption was similar in the two studies $(72.3 \pm 2.4$ vs $76.9 \pm 2.4 \mathrm{cal} / \mathrm{h}$; $p>0.05)$.

Non-protein respiratory exchange ratio was slightly but significantly lower during early - as well as late - phase hypoglycaemia $(0.9 \pm 0.01$ vs $0.99 \pm 0.01 ; 210$ $240 \mathrm{~min} ; p<0.05)$ and did not change with time in the two studies.

Calculated glucose oxidation was slightly lower during hypoglycaemia $(3.2 \pm 0.1$ vs $3.9 \pm 0.2 \mathrm{mg}$. $\mathrm{kg}^{-1} \cdot \min ^{-1} ; p<0.05$, at $320-340 \mathrm{~min}$ ) and levels remained stable during the separate studies. However, calculated Rd-nonox was found to be profoundly inhibited by hypoglycaemia, and this was even more pronounced in the later phase $(3.36 \pm 0.54$ vs $6.62 \pm$ $0.67 \mathrm{mg} \cdot \mathrm{kg}^{-1} \cdot \mathrm{min}^{-1} ; \quad p<0.001,210-240 \mathrm{~min}$ and 
$2.43 \pm 0.41$ vs $7.15 \pm 0.7 \mathrm{mg} \cdot \mathrm{kg}^{-1} \cdot \mathrm{min}^{-1} ; p<0.001$, $320-340 \mathrm{~min}$ ).

Protein oxidation was similar and averaged $0.8 \mathrm{mg} \cdot \mathrm{kg}^{-1} \cdot \mathrm{min}^{-1}$. Insulin infusion suppressed lipid oxidation to a greater extent during euglycaemia when compared to hypoglycaemia $(0.11 \pm 0.05$ vs $\left.0.30 \pm 0.07 \mathrm{mg} \cdot \mathrm{kg}^{-1} \cdot \min ^{-1} ; p<0.05 ; 320-340 \mathrm{~min}\right)$.

\section{Discussion}

This study focuses on the role of glycogen synthase activity in the reduction of glucose uptake during hypoglycaemia. We found total $\mathrm{Rd}$ to be reduced to about $50 \%$ of euglycaemic values. The activity of glycogen synthase in skeletal muscle was reduced by $80 \%$ during hypoglycaemia, i. e. to a level comparable to that found in the basal state [21], and Rd-nonox was substantially suppressed. Due to the limitations of the isotope dilution technique in its present form, "physiologically impossible" negative values for HGP occur. Therefore, these data should be interpreted qualitatively rather than quantitatively. Bearing this in mind, hypoglycaemia seemed to exert a stimulating effect on HGP.

Under conditions of euglycaemic hyperinsulinaemia, muscle has been shown to account for up to $85 \%$ of the amount of glucose to be metabolized [33]. In recent studies, we and others $[18,19]$ have shown forearm glucose uptake to be dramatically reduced during hyperinsulinaemia-induced hypoglycaemia, and the present study implicates a pivotal role for the profoundly reduced muscle glycogen synthase activity in this condition.

The role of decreased mass action of glucose [34] also demands consideration. Hyperglycaemia (glucose per se) has been suggested to stimulate Rd-nonox and to a lesser extent Rd-ox [35], whereas no such stimulating effect has been demonstrated on glycogen synthase activity [36]. Even though these results cannot be directly extrapolated to the hypoglycaemic setting of the present study, the fact that Rd decreased even before any significant counterregulatory hormonal release was evident (at a plasma glucose level of $4 \mathrm{mmol} / \mathrm{l}$ ) point towards an independent effect of a reduction in the plasma glucose level to reduce glucose uptake. This is supported in a recent study by Capaldo et al. [19] demonstrating a reduced glucose mass effect in forearm experiments.

Non-oxidative glucose metabolism has several possible pathways: 1) formation of glycogen, 2) anaerobic glycolysis and subsequent lactate formation, 3) conversion into lipids. The amount of lactate released from muscle in response to insulin is small, even during moderate hypoglycaemia $[18,19,33]$, and presumably only small amounts of glucose are converted into lipids [37], and the major fate for glu- cose taken up into muscle has been ascribed to glycogen synthesis. In support of this, a positive correlation has been found between glycogen synthase activity and Rd-nonox $[38,39]$ and by using nuclear magnetic resonance spectroscopy. Shulman et al. [40] have shown that under conditions of euglycaemic hyperinsulinaemia glycogen synthesis represents the primary pathway for Rd-nonox.

Several of the participants in the counter-regulatory set-up could be responsible for the inhibitory effect of hypoglycaemia on glycogen synthase activity and Rd-nonox.

Epinephrine acts in defence against short-term as well as long-term hypoglycaemia and has been demonstrated to antagonize insulin action on muscular tissue [41].

Insulin stimulation of phosphatase-1 (PP-1) which activates glycogen synthase has been shown to be a result of a phosphorylation at site- 1 of the glycogenbinding G-subunit of PP-1 [42]. In contrast, the cyclic AMP-dependent kinase (activated by e.g. catecholamines) phosphorylates both sites- 1 and -2 of the Gsubunit, and activates the specific inhibitor of PP-1, thereby inactivating PP-1 [42, 43]. It is in agreement with this observation to hypothesize that insulin stimulation of muscle glycogen synthase may be blocked by elevated plasma epinephrine levels during hypoglycaemia.

In a study where epinephrine was infused during euglycaemic hyperinsulinaemia Raz et al. [44] found that epinephrine inhibits insulin-mediated glycogenesis. This was associated with an inactivation of glycogen synthase and activation of glycogenolysis, which is in agreement with our results. They found an increase in G 6-P, which inhibits hexokinase and thereby glucose uptake, and enhances glycolysis.

In the present study the G 6-P content was also increased during hypoglycaemia and even though the difference in calculated intracellular glucose content did not reach statistical significance, this fits well with the inhibition of glycogen synthase activity and non-oxidative glucose metabolism. We could not demonstrate increased glycolysis when measuring Rd-ox; whether this could be explained by the hypoglycaemia-associated impairment of glucose mass action and subsequent lack of oxidation is unclear. Studies on isolated intact rat muscle support the role of epinephrine in inbibition of insulin-mediated glycogen synthesis and activation of glycogenolysis through activation of glycogen phosphorylase [45, 46].

In a model of prolonged ( $8-\mathrm{h})$ hypoglycaemia and relatively low-dose insulin infusion $\left(0.4 \mathrm{mU} \cdot \mathrm{kg}^{-1}\right.$. $\min ^{-1}$ ), Fanelli et al. [47] have demonstrated that a significant part of the catecholamine-induced suppression of $\mathrm{Rd}$ may be due to increased lipolysis, leading to increased levels of NEFA and glycerol. In the present study the higher insulin infusion rate 
leading to suppression of NEFA levels presumably prevented indirect mediation $[48,49]$ from playing any major role (a notion supported by the very modest elevation of lipid-oxidation during hypoglycaemia).

Concerning the role of $\mathrm{GH}$ and cortisol, $\mathrm{GH}$ has been found to inhibit insulin-mediated activation of glycogen synthase in skeletal muscle [21] and, also in agreement with the findings in the present study, to inhibit glucose oxidation in favour of lipid oxidation. The effect of $\mathrm{GH}$ on muscle has been shown to be delayed by approximately $2 \mathrm{~h}$ and part of its effect has been suggested to be direct, rather than dependent on lipolysis [50].

Previously cortisol was thought to play only a minor role in short-term counter-regulation. However, in a study of prolonged hypoglycaemia, De Feo et al. [51] demonstrated a significant cortisol-induced stimulation of HGP after $3 \mathrm{~h}$ and a significant inhibition of glucose utilisation after $4 \mathrm{~h}$. Some of these effects might be secondary to stimulation of lipolysis. Apart from the indirectly mediated effects, cortisol has been shown to reduce the speed by which insulin activates glucose transporters and also to mediate the effect of insulin at a post-binding level $[52,53]$. In vitro studies have shown long-term dexamethasone treatment (14 days) to be associated with an inhibition of insulin-stimulated glycogen synthesis and a decrease in glycogen synthase activity in muscle. The reduction in glycogen synthesis was associated with increased NEFA levels [54].

Calculation of glucose-, lipid- and protein-oxidation from indirect calorimetry data is based on a number of assumptions, and in particular ongoing lipogenesis and gluconeogenesis may influence results [22], necessitating cautious interpretation. In a doseresponse study on the relationship between plasma insulin concentration and total $\mathrm{Rd}, \mathrm{Rd}-\mathrm{ox}$ and $\mathrm{Rd}-$ nonox [55], Rd-nonox was found to represent the major route of glucose disposal during euglycaemic hyperinsulinaemia, and glucose oxidation was saturated at lower plasma insulin concentrations than glucose storage. In the present study hypoglycaemia especially compromised the route of $\mathrm{Rd}$-nonox, a fact which seems logical, considering that insulin exerts its major influence here.

Recently, Shamoon et al. [56] demonstrated muscle glycogen synthase activity to be suppressed and G 6-P content to be increased in non-insulin-dependent diabetic subjects during insulin-induced hypoglycaemia, placing skeletal muscle in a key position in counter-regulation in these subjects. In the control subjects, however, only a minor increase in G 6-P content was found and glycogen synthase activity was unsuppressed. This apparent discrepancy between both our results is probably explained by the presence of higher insulin levels in the study by Shamoon et al. [56] and also it cannot be excluded that some suppression of glycogen synthase activity would have been unmasked if a constant euglycaemic control situation had been present. Our results are in agreement with those of a very recent study by Cohen et al. [20], demonstrating decreased glycogen synthesis in skeletal muscle during mild hypoglycaemia and physiological hyperinsulinaemia in healthy subjects.

The small difference in insulin levels (684 \pm 60 vs $756 \pm 30 \mathrm{pmol} / \mathrm{l} ; p<0.05$ ) in our study cannot account for the pronounced suppression of glycogen synthase activity and non-oxidative glucose disposal $[36,55]$. However, the difference was slightly greater than would have been expected from suppression of endogenous insulin production, and could possibly reflect an elevated clearance of insulin during hypoglycaemia, even though this to our knowledge has not previously been described.

In conclusion, in accordance with the finding of a prominent reduction of $\mathrm{Rd}$-nonox our data suggest that hypoglycaemia virtually abolishes the effect of supraphysiological insulin exposure on muscle glycogen synthase activity.

Acknowledgements. We thank Ms. A. Mengel, Ms. L. Blak, Ms. I. Bisgaard for expert technical assistance and Ms. A. Andersen for excellent assistance in preparation of the manuscript.

\section{References}

1. Cryer PE, Gerich JE (1985) Glucose counterregulation, hypoglycaemia and intensive insulin therapy in diabetes mellitus. N Engl J Med 313: 232-241

2. Campbell PJ, Gerich JE (1988) Mechanisms for prevention, development and reversal of hypoglycaemia. Adv Intern Med 33: 205-230

3. Gerich JE (1985) Sulfonylureas in the treatment of diabetes mellitus. Mayo Clin Proc 60: 439-443

4. Koch J, Muhlhauser I, Jorgens Vet al. (1993) Incidence and management of severe hypoglycaemia in 403 type 1 (insulin-dependent) diabetic patients: follow-up 18 months after an intensified teaching and treatment programme. Diabetologia 25 (2): 171-172

5. Deckert T, Paulsen J, Larsen M (1978) Prognosis of diabetics with diabetes onset before the age of 31 . Survival, cause of death and complications. Diabetologia 14: 363-370

6. The DCCT research group (1993) The effect of intensive treatment of diabetes on the development and progression of long-term complications in insulin-dependent diabetes mellitus. N Engl J Med 329: 977-986

7. Sacca L, Sherwin R, Hendler R, Felig P (1979) Influence of continuous physiologic hyperinsulinemia on glucose kinetics and counterregulatory hormones in normal and diabetic man. J Clin Invest 63: 849-857

8. Rizza A, Cryer P, Gerich JE (1979) Role of glucagon, catecholamines and growth hormone in human glucose counterregulation: effects of somatostatin and combined $\alpha$ - and $\beta$-adrenergic blockade on plasma glucose recovery and glucose flux rates after insulin-induced hypoglycaemia. J Clin Invest 64: 62-71

9. De Feo P, Perriello G, De Cosmo S et al. (1986) Comparison of glucose counterregulation during short-term and 
prolonged hypoglycaemia in normal humans. Diabetes 35 : 563-569

10. De Feo P, Perriello G, Ventura MM et al. (1987) The pancreatic-adrenocortical-pituitary clamp technique for study of counterregulation in humans. Am J Physiol 252: E565-E570

11. Bolli G, De Feo P, Perriello G et al. (1985) Role of hepatic autoregulation in the defence against hypoglycaemia in man. J Clin Invest 75: 1623-1631

12. Randle P, Garland P, Hales Cet al. (1963) The glucose-fatty acid cycle: its role in insulin sensitivity and the metabolic disturbance of diabetes mellitus. Lancet I: 785-789

13. Ferrannini E, Barrett EJ, Bevilacqua S et al. (1983) Effects of fatty acids on glucose production and utilisation in man. J Clin Invest 72: 1737-1747

14. Caprio S, Amiel S, Tamborlane WT, Gelfand AG, Sherwin $S$ (1990) Defective free-fatty acid and oxidative glucose metabolism in IDDM during hypoglycaemia; influence of glycemic control. Diabetes 39: 134-141

15. Frizzell R, Campbell R, Cherrington A (1988) Gluconeogenesis and hypoglycaemia. Diabetes Metab Rev 4: 51-54

16. Caprio S, Sacca L, Tamborlane WV, Sherwin R (1988) Relationship between changes in glucose production and gluconeogenesis during mild hypoglycemia in humans. Metabolism 37: 707-710

17. Lecavalier L, Bolli G, Cryer P, Gerich J (1989) Contributions of gluconeogenesis and glycogenolysis during glucose counterregulation in normal humans. Am J Physiol 256: E844-E851

18. Abildgaard N, Ørskov L, Petersen JAK, Alberti KGMM, Schmitz O, Møller N (1995) Forearm substrate exchange during hyperinsulinaemia hypoglycaemia in humans. Diabet Med 12: 218-223

19. Capaldo BR, Napoli R, Guida R et al. (1995) Forearm muscle insulin resistance during hypoglycemia: role of adrenergic mechanisms and hypoglycemia per se. Am J Physiol 268: E248-E254

20. Cohen N, Rossetti L, Shlimovich P, Halberstam M, Hu M, Shamoon H (1995) Skeletal muscle glycogen metabolism during three hours of physiological hyperinsulinemia in humans. Diabetes 44: 423-430

21. Bak JF, Møller N, Schmitz O (1991) Effects of growth hormone on fuel utilisation and muscle glycogen synthase ac tivity in normal humans. Am J Physiol 260: E736-E742

22. Frayn KN (1983) Calcullation of substrate oxidation rates in vivo from gaseous exchange. J Appl Physiol 55: 628-631

23. Orskov H, Thomsen AG, Yde H (1968) Wick-chromatography for rapid and reliable immunoassay of insulin, glucagon and growth hormone. Nature 219: 193-195

24. Andersen L, Dinesen B, Jørgensen PN, Paulsen F, Røder ME (1993) Enzyme immunoassay for intact human insulin in serum or plasma. Clin Chem 39:578-582

25. Erikkson BM, Persson AB (1982) Determination of catecholamines in rat heart tissue and plasma samples by liquid chromatography. J Chrom Biomed App 228: 143-154

26. Harrison J, Hodson AW, Skillin AW, Strappenbeck R, Ageus L, Alberti KGMM (1988) Blood glucose, lactate, pyruvate, glycerol, 3-hydroxy-butyrate and acatoacetate measurements in man using a centrifugal analyser with a fluorometric attachment. J Clin Chem Clin Biochem 26: 141146

27. Bak JF, Pedersen O (1990) Exercise-enhanced activation of glycogen synthase in human skeletal muscle. Am J Physiol 258: E957-E963

28. Kochan RG, Lamb DR, Lutz DR, Perril CV, Reiman EM, Schendler KK (1979) Glycogen synthase activation in human skeletal muscle: effects of diet and exercise. Am J Physiol 236: E660-E666
29. Lowry OH, Passonneau JV (1972) A flexible system of enzymatic analysis. Academic Press New York

30. Sjögaard G, Adams RP, Saltin BR (1985) Water and ion shifts in skeletal muscle of humans with intense dynamics knee extension. Am J Physiol 248: R190-R196

31. Steele R (1959) Influence of glucose loading and of injected insulin on hepatic glucose output. Ann NY Acad Sci 82: $420-424$

32. De Bodo R, Steele R, Altschuler N, Dunn A, Bishop J (1963) On the hormonal regulation of carbohydrate metabolism: studies with C14 glucose. Recent Progr Horm Res 19: $445-488$

33. DeFronzo RA, Jacot E, Jequier E, Maeder E, Wahren J, Felber JP (1981) The effect of insulin on the disposal of intravenous glucose; results from indirect calorimetry and hepatic and femoral venous catheterisation. Diabetes 30 : 1000-1007

34. Verdonk C, Rizza RA, Gerich JE (1981) Effects of plasma glucose concentration on glucose utilisation and glucose clearance in normal man. Diabetes 30: 535-537

35. Yki-Jarvinen H, Bogardus C, Howard BV (1987) Hyperglycaemia stimulates carbohydrate oxidation in humans. Am J Physiol 253: E376-E382

36. Yki-Jarvinen H, Mott D, Young AA, Stone K, Bogardus C (1987) Regulation of glycogen synthase activity by glucose and insulin in human skeletal muscle. J Clin Invest 80: 95100

37. Bjorntorp P, Sjostrom L (1978) Carbohydrate storage in man; speculation and some quantitative considerations. Metabolism 27 [Suppl 2]: 1853-1865

38. Bogardus C, Lillioja S, Stone K, Mott D (1984) Correlation between muscle glycogen synthase activity and insulin action in man. J Clin Invest 73: 1185-1190

39. Mandarino LJ, Wright KS, Verity LS et al. (1987) Effects of insulin on human skeletal muscle pyruvate dehydrogenase, phosphofructokinase and glycogen synthase; evidence for their role in oxidative and nonoxidative glucose metabolism. J Clin Invest 80: 655-663

40. Shulman GI, Rothman DL, Jue T, Stein P, DeFronzo RA, Shulman RG (1990) Quantitation of muscle glycogen synthesis in normal subjects and subjects with non-insulin-dependent diabetes by $13 \mathrm{C}$ nuclear magnetic resonance spectroscopy. N Engl J Med 322: 223-228

41. Capaldo B, Napoli R, Di Marino L, Sacca L (1992) Epinephrine directly antagonizes insulin-mediated activation of glucose uptake and inhibition of free fatty acid release in forearm tissues. Metabolism 41: 1146-1149

42. Dent P, Lavoinne A, Nakielny S, Caudwell FB, Watt P, Cohen $\mathrm{P}$ (1990) The molecular mechanism by which insulin stimulates glycogen synthesis in mammalian skeletal muscle. Nature 348: 302-308

43. Nakielny S, Campbell DG, Cohen P (1991) The molecular mechanism by which adrenaline inhibits glycogen synthesis. Eur J Biochem 199: 713-722

44. Raz I, Katz A, Spencer M (1991) Epinephrine inhibits insulin-mediated glycogenesis but enhances glycolysis in human skeletal muscle. Am J Physiol 260: E430-E435

45. Challiss RAJ, Crabtree B, Newsholme EA (1987) Hormonal regulation of the rate of the glycogen/glucose-1-phosphate cycle in skeletal muscle. Eur J Biochem 163: 205-210

46. James DE, Burleigh KM, Kraegen EW (1986) In vivo glucose metabolism in individual tissues of the rat. $\mathrm{J}$ Biol Chem 261: 6366-6374

47. Fanelli CG, De Feo P, Porcellati F et al. (1992) Adrenergic mechanisms contribute to the late phase of hypoglycaemic glucose counterregulation in humans by stimulating lipolysis. J Clin Invest 89: 2005-2013 
48. Fanelli C, Calderone S, Epifano L et al. (1993) Demonstration of a critical role for free fatty acids in mediating counterregulatory stimulation of gluconeogenesis and suppression of glucose utilisation in humans. J Clin Invest 92 : 1617-1622

49. Fanelli C, Pampanelli S, Ciofetta M, Del Sindaco P, Lepore M, Bolli GB (1995) Sustained lipolysis is largely responsible for post-hypoglycemic insulin resistance in humans. Diabetes 44 [Suppl]: 4 (Abstract)

50. Møller N, Butler PC, Antsiferov MA, Alberti KGMM (1989) Effects of growth hormone on insulin sensitivity and forearm metabolism in normal man. Diabetologia 32: $105-110$

51. De Feo P, Perriello G, Torlone E et al. (1989) Contribution of cortisol to glucose counterregulation in humans. Am J Physiol 257: E35-E42

52. Rizza RA, Mandarino LJ, Gerich JE (1981) Cortisol-induced insulin resistance in man: impaired suppression of glucose production and stimulation of glucose utilisation due to a postreceptor defect of insulin action. J Clin Endocrinol Metab 54: 131-138

53. Baron AD, Wallace $P$, Brechtel $G$ (1987) In vivo regulation of non-insulin-mediated and insulin-mediated glucose uptake by cortisol. Diabetes 36: 1230-1237

54. Corderre L, Srivastava AS, Chiasson J-L (1992) Effect of hypercorticism on regulation of skeletal muscle glycogen metabolism by insulin. Am J Physiol 262: E427-E433

55. Thiebaud D, Jacot E, DeFronzo RA, Maeder E, Jequier E, Felber J (1982) The effect of graded doses of insulin on total glucose uptake, glucose oxidation and glucose storage in man. Diabetes 31: 957-963

56. Shamoon H, Friedman S, Canton C, Zacharowicz L, Hu M, Rossetti L (1994) Increased epinephrine and skeletal muscle responses to hypoglycemia in non-insulin-dependent diabetes mellitus. J Clin Invest 93: 2562-2571 